\title{
Characterization of Nutrient Disorders and Impacts on Chlorophyll and Anthocyanin Concentration of Brassica rapa var. Chinensis
}

\author{
Patrick Veazie ${ }^{1}$, Paul Cockson ${ }^{1}{ }^{\oplus}$, Josh Henry ${ }^{1,+}{ }^{+}$Penelope Perkins-Veazie ${ }^{2}$ and \\ Brian Whipker ${ }^{1, *}$ \\ 1 Department of Horticultural Sciences, North Carolina State University, Raleigh, NC 27695, USA; \\ phveazie@ncsu.edu (P.V.); pncockso@ncsu.edu (P.C.); josh.brady.henry@gmail.com (J.H.) \\ 2 Plants for Human Health Institute, North Carolina State University, Kannapolis, NC 28081, USA; \\ penelope_perkins@ncsu.edu \\ * Correspondence: bwhipker@ncsu.edu \\ + Current address is: The Scotts Miracle-Gro Company, Marysville, $\mathrm{OH} 43040$, USA.
}

Received: 3 September 2020; Accepted: 5 October 2020; Published: 8 October 2020

\begin{abstract}
Essential plant nutrients are needed at crop-specific concentrations to obtain optimal growth and yield. Foliar tissue analysis is the standard method for assessing nutrient levels in plants. Symptoms of nutrient deficiency or toxicity occur when the foliar tissue values become too low or high. Diagnostic nutrient deficiency criteria for Brassica rapa var. Chinensis (bok choy) is lacking in the current literature. In this study, green ('Black Summer') and purple ('Red Pac') bok choy plants were grown in silica sand culture, with control plants receiving a complete modified Hoagland's all-nitrate solution, and nutrient-deficient plants induced by using a complete nutrient formula withholding a single nutrient. Tissue samples were collected at the first sign of visual disorder symptoms and analyzed for dry weight and nutrient concentrations of all plant essential elements. Six weeks into the experiment, the newest matured leaves were sampled for chlorophyll $a, b$, and total carotenoids concentrations for both cultivars, and total anthocyanin concentration in 'Red Pac'. Compared to control plants, the dry weight of 'Black Summer' green bok choy was significantly lower for nitrogen $(\mathrm{N})$, phosphorus $(\mathrm{P})$, calcium $(\mathrm{Ca})$, or boron $(\mathrm{B})$ deficiency treatments, and nutrient concentrations were lower for all variables except iron (Fe) deficiency. Dry weight was less in 'Red Pac' plants grown without $\mathrm{N}$, potassium $(\mathrm{K}), \mathrm{Ca}, \mathrm{B}$, or molybdenum (Mo), and nutrient concentrations were lower for all except Mo-deficiency compared to controls. Total chlorophyll and total carotenoid concentrations were lower in leaves from $\mathrm{N}-, \mathrm{Fe}-$, and manganese- $(\mathrm{Mn})$ deficient plants of both cultivars. Leaf anthocyanin concentration was lower only for K-, Ca-, and B-deficiencies in 'Red Pac'. Our results indicate that visual symptoms of nutrient deficiency are well correlated with nutrient disorders. In contrast, changes in dry weight, chlorophyll, and anthocyanin did not show consistent changes across nutrient disorders.
\end{abstract}

Keywords: toxicity; deficiency; macronutrients; micronutrients; nutrient disorders; tissue analysis; bok choy; carotenoids

\section{Introduction}

Plant tissue analysis has been used extensively to evaluate the nutritional status of a crop, nutrient sufficiency levels, and recommended rates and types of fertilizer [1]. Visual symptoms can be used as indicators of a specific mineral deficiency and have proved to be useful in assisting growers in making fertility adjustments. However, foliar analysis is needed to determine fertility adjustments to avoid over or underapplication [2]. 
The genus Brassica belongs to the crucifer or brassicacea family and is economically the most important genus within its family [3]. Brassica rapa var. Chinensis (bok choy) is available as green, dark purple, and red cultivars. Nitrogen $(\mathrm{N})$ application recommendations for bok choy range from 100 to $250 \mathrm{~kg} \mathrm{Nha}^{-1}$, with an optimum concentration of $200 \mathrm{~kg} \mathrm{Nha}^{-1}[4,5]$. The lowest possible application rate of $\mathrm{N}$ is the most economically appealing for growers. However, growers producing Brassica rapa var. Chinensis can encounter problems if other specific mineral nutrient disorders manifest that render the crop unfit for market or simply unattractive to consumers.

Anthocyanins (flavonoids) are water-soluble pigments that accumulate in leaves, petals, sepals, and fruits of plants, providing color, photoprotection, herbivory, and pathogen defense, signal transduction, and water relations [6,7]. Additionally, in human health, anthocyanins protect against cardiovascular disease, diabetes, cancer, and vision loss in humans [8]. Phenolic compounds, including flavonoid precursors, are synthesized in the cytoplasm via the phenylpropanoid pathway and compartmentalized in the vacuole. In bok choy, the primary anthocyanins are acylated cyanidin-3-glucosides [9]. While changes in anthocyanin content of Pac Choi 'Mei Qing Choi', a close relative of bok choy, relative to nutrient stress have not been reported, the total phenolic content of bok choy was reported to increase with $\mathrm{N}$-deficiency Zhao et al. [10]. Betalain, a pigment similar to anthocyanin, increased with a P-deficiency in alternanthera [7]. Mineral nutrients may play an indirect role by promoting photosynthesis and increased sugars for use in anthocyanin synthesis or by increasing pigment per unit leaf weight, due to limited leaf expansion [11]. Minerals may play a direct role by promoting flavonoid synthesis as cofactors for enzymes or stabilize anthocyanins through pigment-metal complexes [12].

Chlorophyll (Chl) molecules ( $\mathrm{Chl}$ a and $\mathrm{Chl}$ b) in the chloroplast are needed for the transformation of light energy to chemical bonds in plants [13], while carotenoids, such as lutein, zeaxanthin, and violaxanthin, provide photoprotection [14]. The leaf Chl concentration is an important physiological indicator of plant stress [15]. Reduced Chl concentrations may limit the photosynthetic processes and further decrease in the primary production of Chl [16]. Plant Chl concentration plays a major role as a visual indicator of mineral nutrient deficiencies, often expressed in leaf color changes from dark green to light green or yellow. Relative chlorophyll content (RCC) estimates total chlorophyll that can be measured easily and non-destructively on leaves and can be used as a rapid means of checking for nutrient stress [17]. As the total $\mathrm{Chl}$ concentration of a crop can occasionally exceed the maximum limits of RCC instruments, chlorophyll content should be established relative to RCC values in a new crop species prior to use for monitoring nutrient stress.

Although tissue nutrient sufficiency values for bok choy have been reported by Bryson and Mills [18], values and symptoms with tissue nutrient deficiencies have not been established. An experiment was conducted to elucidate the nutritional disorder symptomology and determine critical leaf tissue nutrient levels of Brassica rapa var. Chinensis using dark green and red-leaved cultivars. Nutrient deficiencies selected were for macro and micro minerals most commonly encountered in production systems. Additionally, the treatment of excess boron was added as this mineral can cause mineral toxicity. The impact of nutrient deficiencies on RCC, Chl, and anthocyanin concentration in bok choy leaves was also evaluated to determine if these values would be useful as early indicators of nutrient stress.

\section{Materials and Methods}

\subsection{Plant Materials}

Two bok choy cultivars (Brassica rapa var. Chinensis 'Red Pac' and 'Black Summer') (Johnny's Select Seeds; Winslow, ME, USA) were planted 28 April 2019 into 128 count trays $(4 \times 2.3 \times 2.3 \mathrm{~cm}$ (cell size), and germinated in a mist bench for two weeks. Seedlings were transplanted into 12.7 $\mathrm{cm}$-diameter $(0.76 \mathrm{~L}$ ) plastic pots containing silica-sand (Millersville \#2 (0.8 to $1.2 \mathrm{~mm}$ diameter) from Southern Products and Silica Co., Hoffman, NC, USA) on 17 May 2019. The plants were grown in 
a glass greenhouse with $26^{\circ} \mathrm{C}$ and $20^{\circ} \mathrm{C}$ day/night in Raleigh, $\mathrm{NC}\left(35^{\circ} \mathrm{N}\right.$ latitude). Immediately after transplanting, treatments were initiated using an automated, recirculating irrigation system that was constructed out of $10.2 \mathrm{~cm}$ diameter PVC pipe (Charlotte Plastics, Charlotte, NC, USA). Detailed information about the formulation of the fertilizer treatments, salts used, and the system is given in Barnes et al. [19].

When the initial visual deficiency symptoms of each treatment occurred, three plant replicates that exhibited symptoms were selected for sampling, and three control plants (referenced as All for figures) were also sampled. Hence, each sampling contained a corresponding control plant. The remaining four plants were grown to document symptom advancement. The entire shoots were sampled to evaluate the critical tissue concentration for each element. Harvested shoots were washed in a solution of $0.5 \mathrm{M} \mathrm{HCl}$ for $1 \mathrm{~min}$. Shoots were then rinsed with deionized water. The experiment was terminated on 1 July 2019 (six weeks of growth from transplant), in which asymptomatic treatments were sampled for foliar analysis and dry weight for 'Black Summer' plants grown under Molybdenum- (Mo), copper- $(\mathrm{Cu})$, and sulfur- $(\mathrm{S})$ deficient conditions did not exhibit deficiency symptoms. Moreover, 'Red Pac' plants grown under $\mathrm{Cu}$ - and Mo- deficient conditions did not exhibit visual deficiency symptoms. All samples were dried at $70^{\circ} \mathrm{C}$, and dry weights were recorded. Dry tissue was ground to a particle size small enough to pass through a $\leq 0.5 \mathrm{~mm}$ sieve using a Foss Tecator Cyclotec ${ }^{\mathrm{TM}} 1093$ sample mill (Analytical Instruments, LLC, Golden Valley, MN, USA). Tissue analysis was conducted by AgSource Laboratories (Lincoln, NE, USA).

\subsection{Analysis of RCC, Chlorophyll, and Anthocyanin}

The most recently matured leaves were harvested six weeks after the project began (26 June 2019) from three plants of every treatment. Leaves were placed in plastic bags and held at $5-10{ }^{\circ} \mathrm{C}$ during transport to the Plants for Human Health Institute (Kannapolis, NC, USA). Relative Chlorophyll Concentration (RCC) was determined with a chlorophyll meter (SPAD-502; Konica Minolta Sensing, Osaka, Japan) at two locations on each leaf at about $0.5 \mathrm{~cm}$ from the edge at the widest part of the leaf. Leaf weights were taken and frozen at $-20^{\circ} \mathrm{C}$. About $\frac{1}{4}$ to $\frac{1}{2}$ of the leaf, excluding midrib, was placed in $15 \mathrm{~mL}$ polystyrene vials (OPS Diagnostics, Lebanon, NJ, USA) with two $9 \mathrm{~mm}$ stainless steel balls (Grainger, Charlotte, NC, USA) and ground in a genogrinder (SPEX, Boston, MA, USA) for 2 min at 400 strokes/min. The ground material was transferred to microvials. For chlorophyll, $\sim 0.005 \mathrm{~g}$ of the leaf was added to $2 \mathrm{~mL}$ sealing vials (Sigma-Aldrich, Milwaukee, WI, USA) equipped with two $2 \mathrm{~mm}$ stainless steel balls and extracted with $2 \mathrm{~mL}$ of $95 \%$ by volume ethanol using a multi vortexor (Grant-Bio V32, Fisher Scientific, Hampton, NH, USA) followed by 5 min sonication (Branson Ultrasonicator, Dansbury, CT, USA). Vials were centrifuged at $10,000 \times g$ at $4{ }^{\circ} \mathrm{C}$ for $10 \mathrm{~min}$ in a microcentrifuge (Eppendorf 5471R, Ocala, FL, USA). One mL of supernatant was used to determine the absorbance at 470.0,648.6, 664.1, and 750.0 $470.0 \mathrm{~nm}$ using a spectrophotometer (UV-Vis 2450, Shimadzu, Columbia, MD, USA). Chl a, b, total Chl, and total carotenoids were determined by using the formula of Lichtenthaler ([20]) as outlined below.

$$
\begin{aligned}
& \text { Chl a }(\mathrm{mg} / \mathrm{g})=0.001 \times((13.36 \times(\mathrm{A} 664.1-\mathrm{A} 750)-5.19 \times(\mathrm{A} 648.6-\mathrm{A} 750) \times(\text { mls extraction } \\
& \text { solvent weight/g sample weight)) } \\
& \text { Chl b }(\mathrm{mg} / \mathrm{g})=0.001 \times((27.43 \times(\mathrm{A} 648.6-\mathrm{A} 750)-8.12 \times(\mathrm{A} 664.1-\mathrm{A} 750) \times(\text { mls extraction } \\
& \text { solvent weight/g sample weight)) } \\
& \text { Total Chl }(\mathrm{mg} / \mathrm{g})=\mathrm{Chl} \mathrm{a}+\mathrm{Chl} b
\end{aligned}
$$

where $\mathrm{df}=(\mathrm{mls}$ extraction solvent/g sample weight). 
As the red pigment in red-leaved bok choy is from anthocyanins [10], the $\mathrm{pH}$ differential method [21] was used to determine the anthocyanin concentration in 'Red Pac' leaves. Frozen leaf tissue ( 0.03 to $0.05 \mathrm{~g}$ ) was quickly placed into $2 \mathrm{~mL}$ vials, with $1.5 \mathrm{~mL}$ of $\mathrm{pH} 1.0$ potassium chloride $(\mathrm{KCl})$ buffer or $\mathrm{pH} 4.5$ sodium acetate $\mathrm{CH}_{3}(\mathrm{OONa})$ buffer added and samples vortexed at room temperature for $10 \mathrm{~min}$ (Mortexor, Bench Mark Scientific, Edison, NJ, USA). Vials were spun in a microcentrifuge at $10,000 \times g$ at $4{ }^{\circ} \mathrm{C}$ and $1 \mathrm{~mL}$ supernatant used to determine the absorbance at 520 and $700 \mathrm{~nm}$ using a spectrophotometer (Shimadzu Model 2450, Columbia, MD, USA). Absorbance was used to cyanidin-3-glucoside equivalents using the formula:

$$
\begin{gathered}
\text { Anthocyanin }(\mathrm{mg} / \mathrm{kg} \text { fresh weight })=(\text { Abs520 pH1.0 }- \text { Abs 700pH1.0 })-(\text { Abs520 pH4.5 - } \\
\text { Abs } 700 \mathrm{pH} 4.5) \times(\text { mls buffer/tissue weight }(\mathrm{g}))
\end{gathered}
$$

\subsection{Statistical Analysis}

This study was a completely randomized design, and statistical analysis was carried out using SAS (version 9.4; SAS inst., Cary, NC, USA). Plant growth metrics, leaf nutrient values, chlorophyll, and anthocyanin concentrations were analyzed for differences within each data collection regarding nutrient treatment as the explanatory variable using PROC GLM, where $(\mathrm{N}=3)$. Where the F-test was significant, LSD with a Tukey Kramer adjustment $(P<0.05)$ was used to compare differences among means. Deviations in plant metrics, total plant dry weights, leaf tissue values, chlorophyll, and anthocyanin concentrations were calculated on a percentage basis from the controls.

\section{Results and Discussion}

Of the 12 nutrient deficiency treatments and one nutrient toxicity treatment, 'Red Pac' exhibited symptoms for 11 treatments, and 'Black Summer' exhibited symptoms for 10 treatments. Symptoms and shoot dry mass values are reported in Tables S1 and S2. Values for the percentage difference in shoot dry mass are presented in the text if control and treatment tissues were significantly different when symptoms first appeared. Unless otherwise noted, values for tissue concentrations presented were significantly different.

\subsection{Macronutrients}

\subsubsection{Nitrogen $(\mathrm{N})$}

Plants grown under N-deficient conditions first displayed stunting when compared to control plants. The lower leaves of 'Red Pac' were initially slightly pale (Figure 1 and Figure S1), and those of 'Black Summer' were slightly yellow (Figure 2 and Figure S2). As the symptoms progressed, leaves became increasingly pale or yellow. Symptoms first started in the lower leaves and progressed into the middle foliage. With advanced symptoms, leaves became completely yellow, then necrotic, and then abscised.

'Black Summer' plants without N had 60\% less dry mass (Table S1), and 'Red Pac' had 43\% less dry mass than control plants (Table S2). The control $\mathrm{N}$ tissue concentrations were 5.59 and $5.85 \%$ for 'Black Summer' and 'Red Pac' compared to 1.83 and $2.19 \%$ for the N-deficient treatments, respectively (Tables S1 and S2). Visual symptoms for nitrogen-deficiency occurred within 11 days after transplanting and had the most negative long-term growth impact when compared to control plants. This rapid change in appearance and dramatic negative impact in dry weight accumulation underscores the need for growers to monitor nitrogen to obtain maximum crop yield. 


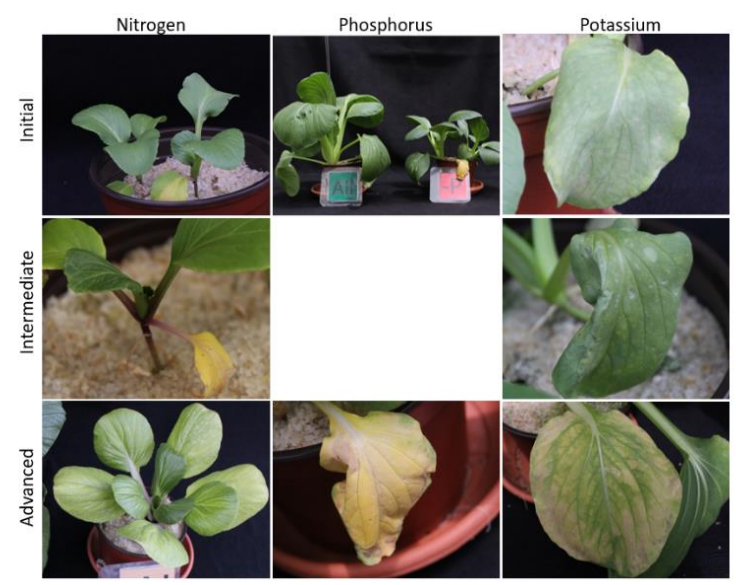

Figure 1. Symptoms of nitrogen-, phosphorus-, and potassium-deficiency in 'Black Summer' plants at initial, intermediate, and advanced stages of symptom development. Symptoms of nitrogen-deficiency were initially expressed 11 days after transplant, phosphorus-deficiency symptoms were observed 16 days after transplant, and potassium-deficiency symptoms were initially expressed 11 days after transplant. Plants were continued to be documented until six weeks after transplant to document initial and advanced symptoms. Note that the "all" plant shown as a comparison shot for initial phosphorus symptoms is a control plant that received a complete Hoagland's solution.

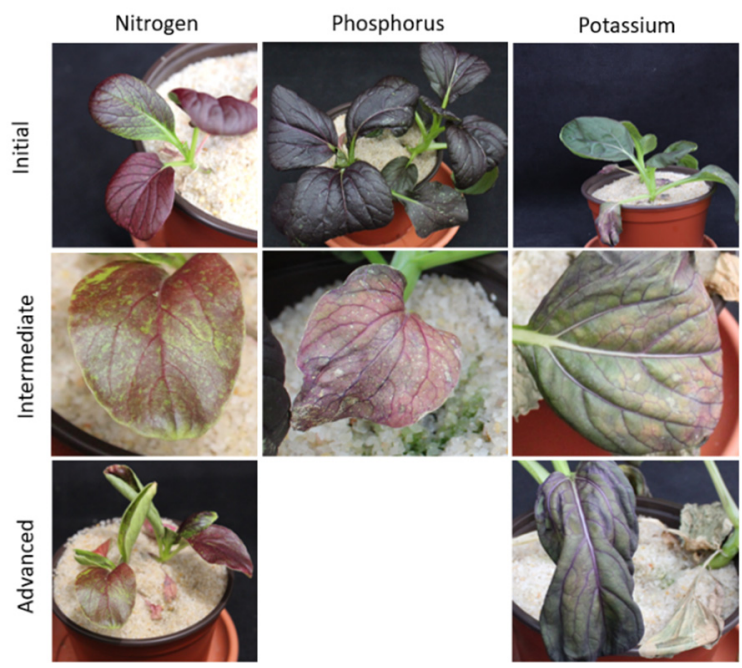

Figure 2. Symptoms of nitrogen-, phosphorus-, and potassium-deficiency in 'Red Pac' bok choy plants at initial, intermediate, and advanced stages of symptom development. Symptoms of nitrogen-deficiency were initially expressed 11 days after transplant, phosphorus-deficiency symptoms were observed 16 days after transplant, and potassium-deficiency symptoms were initially expressed 11 days after transplant. Plants were continued to be documented until six weeks after transplant to document initial and advanced symptoms.

Nitrogen plays a key role in many metabolic and biosynthetic pathways [22] and is one of the most limiting factors in crop yield. Lack of $\mathrm{N}$ would result in fewer new cells in the bok choy and would limit photosynthesis. These impacts of $\mathrm{N}$-deficiency would result in lower $\mathrm{Chl}$ concentrations and dry mass. Chl a, Chl b, and total carotenoid were 76, 65, and 55\% less in 'Black Summer' and 72, 62, and 64\% less in 'Red Pac' N-deficient leaves compared to leaves of the control plants (Tables S3 and S4). The significant difference in $\mathrm{Chl} \mathrm{a} / \mathrm{b}$ ratio for plants grown under $\mathrm{N}$-deficient conditions may be attributed to the increased numbers of grana and thylakoids in chloroplasts with N-deficiency [23].

In several crops, $\mathrm{N}$-deficiency can increase anthocyanin concentrations because of a decrease in cell division [24]. In 'Red Pac' N-deficient bok choy, anthocyanin concentrations were not significantly 
different when compared to control plants (Table S4). This may be the result of fewer and smaller plant cells, resulting in similar concentrations of anthocyanin. These results are in contrast to a prior study [9] in which an increase in anthocyanin concentration of organically grown pak choi 'Mei Qing Choi', a close relative of bok choy, was speculated to be due to an N-deficiency.

\subsubsection{Phosphorus (P)}

Symptoms of P-deficiency manifested on lower leaves and developed as yellowing of the leaf margin accompanied by darker coloration in new growth in both bok choy cultivars (Figures 1 and 2). Irregular spotting patterns also developed on the lower leaves and progressed into irregular spotting and large necrotic regions over time, as well as entire plants being stunted in advanced stages of deficiency. 'Black Summer' plants grown under P-deficient conditions had a 35\% lower dry mass than controls (Table S1). Phosphorus concentration was $0.37 \%$ in control leaves and $0.08 \%$ in P-deficient 'Black Summer' leaves (Table S1). 'Red Pac' had a P concentration of $0.55 \% \mathrm{P}$ in control plants compared to $0.09 \% \mathrm{P}$ in plants grown under P-deficiency (Table S2).

Phosphorus is a mobile element in plants and is utilized for many metabolic pathways in plant growth, photosynthesis, and sugar transport. Increased red foliage pigmentation is one of the primary symptoms associated with P-deficiency [25]. As P is needed for cell growth and division [11], decreased dry mass is expected with a P-deficiency. Although phosphorus is used by plants for photosynthesis, neither $\mathrm{Chl}$ a nor $\mathrm{Chl} \mathrm{b}$ concentrations decreased in either cultivar with $\mathrm{P}$-deficiency. 'Red Pac' anthocyanin concentrations for plants grown under P-deficient conditions were not statistically different when compared to control plants. As $\mathrm{P}$ is a mobile element, it is possible that sampling the newest matured leaves resulted in greater anthocyanin and chlorophyll concentrations in the plant being observed.

\subsubsection{Potassium $(\mathrm{K})$}

Initially, symptoms of K-deficiency in 'Black Summer' appeared as yellowing around the leaf margin of the lower and older foliage. As symptoms progressed, the marginal yellowing in 'Black Summer' became more pronounced, and irregular chlorotic spotting developed (Figure 1). Initial symptoms in 'Red Pac' manifested as an overall paleness in lower and older foliage, and advanced to an overall loss of green and red color, with irregular chlorotic spotting on lower and middle foliage (Figure 2). For both cultivars, spots on the lower and middle foliage became necrotic and abscised in severe cases.

Foliar K concentrations were 94\% lower in K-deficient 'Black Summer' plants and 91\% lower in K-deficient 'Red Pac' plants when compared to control plants (Tables S1 and S2). Dry mass was not significantly different in K-deficient plants for either cultivar when compared to control plants. However, the growth of both cultivars was severely stunted in advanced stages of K-deficiency compared to control plants. K-deficiency will cause plants to close stomata, which limits the $\mathrm{CO}_{2}$ uptake efficiency and accumulation of biomass, as well as decreased cell division [26]. Had the plants been sampled in advanced stages of K-deficiency, a decrease in dry weights would be expected for K-deficient plants of both cultivars when compared to control plants.

Potassium is used to generate enzymes for phosphate metabolism in the production of ATP, a product of photosynthesis [27]. As $\mathrm{K}$ is used in photosynthesis [28], a decrease in Chl concentration was expected in K-deficient plants. Neither bok choy cultivar showed a significant decrease in Chl concentration, perhaps due to $\mathrm{K}$ being a mobile element, it was translocated into the most recently matured leaves in minimal, but adequate, in the lower leaves to avoid impacting Chl production [29].

'Red Pac' bok choy in the K-deficient treatment had 70\% less anthocyanin relative to control plants (Table S4). Potassium stimulates photosynthetic activity and favors the translocation of sugars. This indirectly benefits the synthesis of phenolic components during ripening, which is closely related to the presence of carbohydrates [30]. This would mean that K-deficient plants would have limited ability to translocate sugars and subsequently lower anthocyanin concentration when compared to 
control plants. Additionally, anthocyanins are produced through the phenylpropanoid pathway, which also utilizes ATP as a catalyst, and if ATP is decreased under deficient $K$, the available ATP may be primarily allocated to photosynthesis [31], at the expense of anthocyanin formation.

\subsubsection{Calcium (Ca)}

Symptoms of Ca-deficiency in both bok choy cultivars began with slight stunting of overall growth when compared to control plants. The growing tips of newly expanded leaves demonstrated signs of stunting and irregular growth habits, such as curling and cupping of leaves (Figures 3 and 4, Figures S1 and S2). With advanced symptoms, the new growth was severely limited, and the leaves of Ca-deficient plants were thicker compared to those of control plants. Ca-deficient plants also developed marginal necrosis. In severe cases, the death of the growing tip ceased meristematic expansion and production of new foliage.

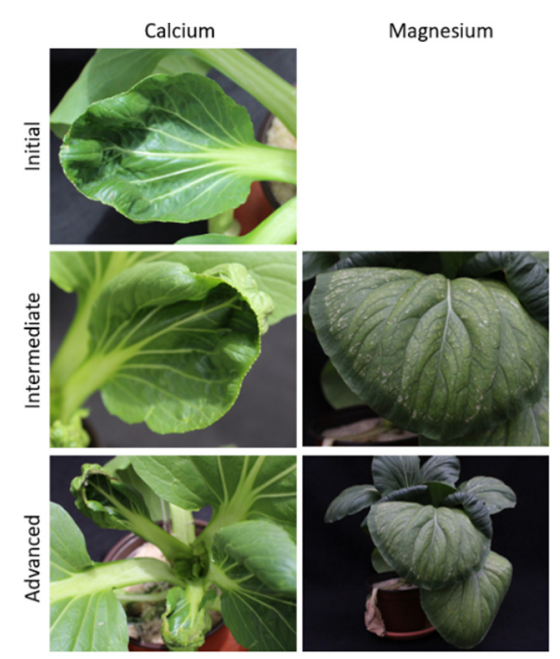

Figure 3. 'Black Summer' bok choy calcium- and magnesium-deficiency at initial, intermediate, and advanced stages of symptom development. Symptoms of calcium-deficiency were initially expressed 24 days after transplant, and magnesium-deficiency symptoms were observed 38 days after transplant. Plants were continued to be documented until six weeks after transplant to document initial and advanced symptoms.

'Black Summer' and 'Red Pac' had $42.5 \%$ and $63.4 \%$ less dry mass, respectively, than the control plants (Tables S1 and S2). Foliar Ca-concentrations was 52.5\% lower in 'Black Summer' and 86.7\% lower in 'Red Pac' compared to the control plants. 'Black Summer' Ca-deficient plants had a foliar Ca concentration of $1.02 \%$ Ca compared to $2.15 \% \mathrm{Ca}$ in control plants (Table S1). 'Red Pac' Ca-deficient plants were much lower in Ca foliar concentration than control plants $(0.39 \%$ and $2.93 \% \mathrm{Ca}$, respectively) (Table S2).

Calcium is a non-mobile element and is utilized by plants in many ways, including cell wall and cell membrane formation. Calcium is needed in cell walls for cell expansion and division, and these functions are blocked when Ca is deficient, with the resulting lack of growth reducing dry mass compared to control plants. Additionally, calcium is utilized in photosynthesis to modulates phosphate enzyme activity in the carbon reduction cycle and is held primarily in the chloroplast [32]. Despite this direct role in the chloroplast, $\mathrm{Chl} \mathrm{b}$ and total carotenoid concentration in leaves from Ca-deficient plants were not significantly different for either cultivar. However, Chl a was 38\% less in 'Black Summer' Ca-deficient plants compared to control plants (Table S3). 'Red Pac' plants grown under Ca-deficient conditions had no significant loss in Chl, while plants had 54\% less anthocyanin concentration when compared to 'Red Pac' control plants (Table S4). 


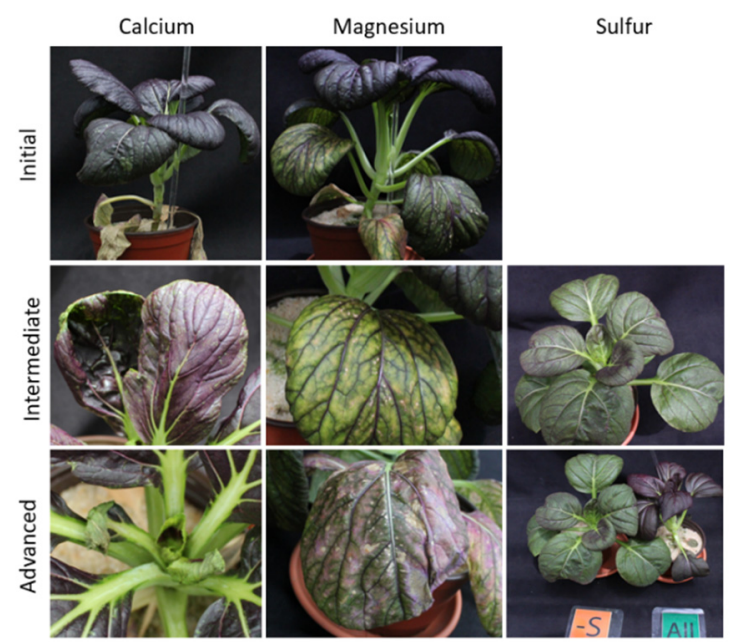

Figure 4. 'Red Pac' bok choy calcium-, magnesium-, and sulfur-deficiency choy at initial, intermediate, and advanced stages of symptom development. Symptoms of calcium-deficiency were initially expressed 24 days after transplant, magnesium-deficiency symptoms were observed 38 days after transplant, and sulfur-deficiency symptoms were initially expressed 22 days after transplant. Plants were continued to be documented until six weeks after transplant to document initial and advanced symptoms. Note that the "all" plant shown as a comparison shot for advanced sulfur symptoms is a control plant that received a complete Hoagland's solution.

\subsubsection{Magnesium (Mg)}

Symptoms of Mg-deficiency were first observed as a slight overall loss of color of the center leaves of 'Black Summer' (Figure 3) and the lower leaves of 'Red Pac' (Figure 4). 'Red Pac' also had leaves that exhibited irregular chlorotic spotting. As symptoms developed, 'Black Summer' developed pale areas in the center region of the leaf, while the leaf margins became darker in appearance. 'Red Pac' exhibited a loss of color, and in severe cases, irregular chlorotic spotting developed into total leaf necrosis and abscission.

Foliar Mg concentrations were $84 \%$ lower in 'Black Summer' and 89.5\% lower in 'Red Pac' in Mg-deficient plants compared to the control plants. Mg-deficient 'Black Summer' plants contained $0.11 \% \mathrm{Mg}$ compared to $0.68 \% \mathrm{Mg}$ for the control plants (Table S1). Mg-deficient 'Red Pac' plants contained $0.10 \% \mathrm{Mg}$ compared to the control plants with $0.65 \% \mathrm{Mg}$ (Table S2). 'Black Summer' had a significantly lower dry mass at sampling when compared to the controls.

Within plants, $\mathrm{Mg}^{2+}$ is the central atom of the Chl molecule and plays a key role in the 'light' and 'dark' steps of photosynthesis [33], and decreased Chl content would be expected in Mg-deficient plants. Chl a, Chl b, and total carotenoid concentration were 47, 44, and 35\% less in 'Black Summer' (Table S3). Chl a, total carotenoids, and anthocyanins in 'Red Pac' Mg-deficient samples were not different from the control plants. However, $\mathrm{Chl} b$ decreased by $19 \%$ for 'Red Pac' plants grown under Mg-deficient conditions when compared to control plants. Magnesium is a mobile element in the plant, so the older foliage would first show a deficiency; as the newest matured leaf was sampled for anthocyanin and chlorophyll, changes in these leaves would be less likely than in older leaves. The lower chlorophyll content in Mg-deficient 'Black Summer' indicates that chloroplast function is immediately impacted. 'Black Summer' is a very dark green cultivar, and while the total chlorophyll concentration of control plants was similar to that of 'Red Pac', chloroplasts in 'Red Pac' may not need as much Mg as 'Black Summer'. As Mg is mobile, it should be most abundant in the newest matured leaves, which would lead to greater Chl concentration [34]. However, if lower leaves were to be sampled, a decrease in Chl would have been observed. 


\subsubsection{Sulfur (S)}

Symptoms of S-deficiency only manifested on 'Red Pac'. S-deficiency was first seen as a slight overall loss of coloration in the foliage beginning in the middle of the plant, although the loss of red coloration was more pronounced at the base of the leaves (Figure 4 and Figure S1). Compared to the respective control plants, S-deficient 'Red Pac' lost most of its red pigment, and older leaves began to turn yellow. As the symptoms developed, the loss of color was more pronounced on the newly expanding leaves. 'Black Summer' did not exhibit any foliar symptoms of S-deficiency by the time the experiment was terminated. Normally S-deficiency is expressed in plants as a slight overall paling; however, these foliar symptoms for 'Black Summer' may have been masked, due to the dark coloration of the leaves.

Although visual symptoms were noted only for 'Red Pac', foliar S concentrations were $92 \%$ and $72 \%$ lower, respectively, for S-deficient 'Black Summer' and 'Red Pac' plants compared to control plants (Tables S1 and S2). Actual foliar S concentrations were 0.1 and $1.3 \%$ in deficient and control 'Black Summer' plants and 0.28 and $1.01 \%$ for S-deficient or control 'Red Pac' plants, respectively (Tables S1 and S2). The dry mass of plants grown in S-deficient conditions was not significantly different from that of control plants for either cultivar.

$\mathrm{Chl}$ a and Chl b were 38 and 37\% less, respectively, in 'Black Summer' (Table S3). Chl a, Chl b, and total carotenoid were 40,33, and 37\% less in 'Red Pac' S-deficient leaves compared to leaves of the control plants. (Table S4). S-deficient 'Red Pac' plants also experienced a 62\% decrease in anthocyanin concentration (Table S4). Sulfur is utilized by plants for Chl formation. Chloroplasts contain proteins rich in S, and chloroplast morphology is greatly impacted by S-deficiency [35]. Since S plays key roles in cell development and morphology, the plant decrease in $\mathrm{Chl}$ a under S-deficient conditions would be expected.

\subsection{Micronutrients}

\subsubsection{Iron $(\mathrm{Fe})$}

The first symptom of Fe-deficiency was a pale appearance in the newly expanding leaves of both cultivars. Both cultivars displayed symptoms primarily in the upper foliage, while the lower foliage displayed healthy coloration. In 'Black Summer', marginal chlorosis developed on newly expanding leaves as plants matured (Figure 5). In 'Red Pac', the appearance of pale color was accompanied by interveinal necrosis primarily in the upper foliage, which advanced to a light pink color, while the lower foliage turned from red to green as plants matured (Figure 6).

'Black Summer' foliar Fe concentration was 39\% less than control values, while dry mass was unaffected when sampled at the initial visual signs of Fe-deficiency (Table S1). The foliar Fe concentrations for 'Red Pac' was $153.4 \mathrm{mg} \cdot \mathrm{kg}^{-1} \mathrm{Fe}$ for control plants and was $73.6 \mathrm{mg} \cdot \mathrm{kg}^{-1} \mathrm{Fe}$ in Fe-deficient plants (Table S2). Total Chl (48\%), carotenoids (30\%), Chl a (48\%), and Chl b (47\%) were lower in 'Black Summer' leaves from Fe-deficient plants as compared to the control (Table S3). 'Red Pac' plants grown under Fe-deficient conditions had significantly lower Chl a (85\%), Chl b (82\%), and total carotenoids (82\%) (Table S4) when compared to control plants.

Plants use Fe in Chl formation, cell division, and growth [36]. The symptomology of Fe-deficient plants is interveinal leaf chlorosis, resulting from decreased efficiency of $\mathrm{Chl}$ and carotenoid production [37]. Iron is both a key element in the synthesis of $\mathrm{Chl}$ and is utilized in the anthocyanin biosynthesis pathway [37]. The total anthocyanin concentration in Fe-deficient 'Red Pac' was low, but not significantly different from control plants. Despite this, iron-deficient plants were bright pink, perhaps from the enhanced contrast that resulted from the decreased leaf $\mathrm{Chl}$ concentration. 


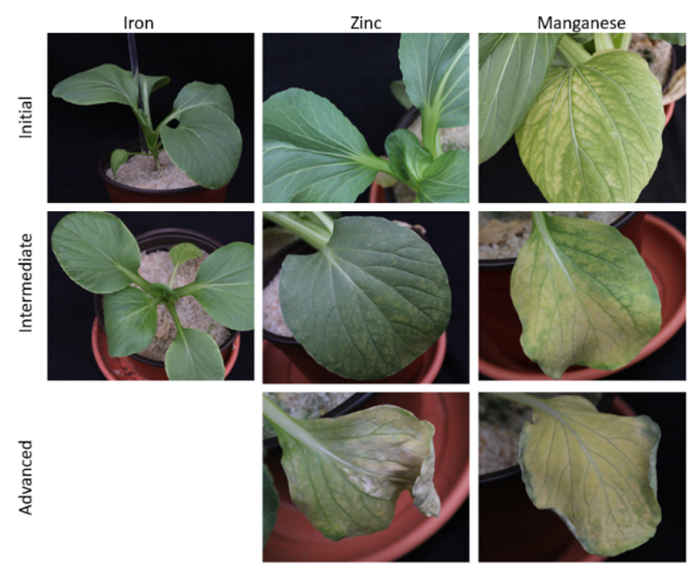

Figure 5. Symptoms of iron-, zinc-, and manganese-deficiency in 'Black Summer' bok choy at initial, intermediate, and advanced stages of symptoms. Symptoms of iron-deficiency were initially expressed 11 days after transplant, zinc-deficiency symptoms were observed 15 days after transplant, and manganese-deficiency symptoms were initially expressed 12 days after transplant. Plants were continued to be documented until six weeks after transplant to document initial and advanced symptoms.
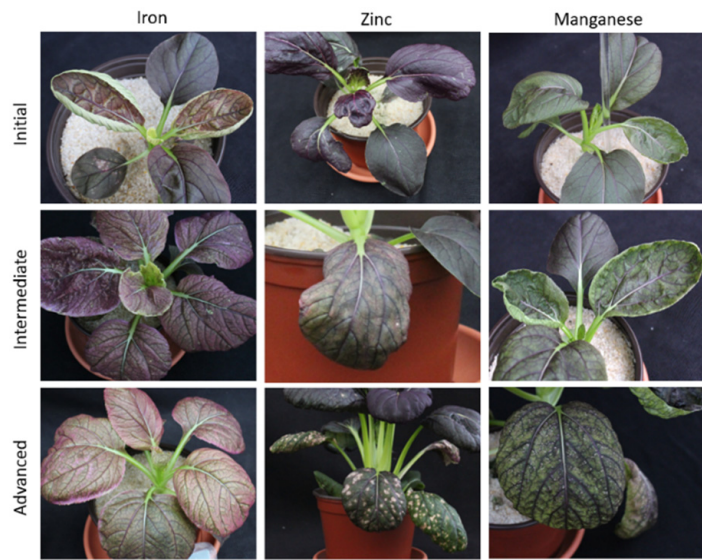

Figure 6. Symptoms of iron-, zinc-, and manganese-deficiency in 'Red Pac' bok choy at initial, intermediate, and advanced stages of symptoms. Symptoms of iron-deficiency were initially expressed 11 days after transplant, zinc-deficiency symptoms were observed 15 days after transplant, and manganese-deficiency symptoms were initially expressed 12 days after transplant. Plants were continued to be documented until six weeks after transplant to document initial and advanced symptoms.

\subsubsection{Zinc $(\mathrm{Zn})$}

Zn-deficient symptoms were first noted as overall pale color in the lower foliage, 'Black Summer' exhibited stunted growth compared to control plants (Figures 5 and 6, Figures S1 and S2). As symptomology advanced, newly developing leaves were distorted and did not fully expand, due to cupping at the leaf margin. 'Red Pac' plants had a decrease in dark pigmentation in the lower foliage, and new foliage appeared to be significantly darker compared to control plants. In 'Black Summer', advanced symptoms manifested as vibrant interveinal chlorosis and the formation of irregular spotting that advanced into tan necrosis in severe cases.

Foliar Zn concentrations for 'Black Summer' grown under Zn-deficient conditions were $8.9 \mathrm{mg} \cdot \mathrm{kg}^{-1}$ $\mathrm{Zn}$ compared to $16.1 \mathrm{mg} \cdot \mathrm{kg}^{-1} \mathrm{Zn}$ in control plants (Table S1). In 'Red Pac', foliar concentrations of Zn were $10.6 \mathrm{mg} \cdot \mathrm{kg}^{-1}$ compared to the control at $15.6 \mathrm{mg} \cdot \mathrm{kg}^{-1} \mathrm{Zn}$ (Table S2). Dry mass was significantly different at sampling for both cultivars (Tables S1 and S2). Chlorophyll concentrations were not different from $\mathrm{Zn}$ treatment in either cultivar (Tables S3 and S4), and total anthocyanin concentration in Zn-deficient 'Red Pac' plants did not differ from the control plants. 


\subsubsection{Manganese (Mn)}

Mn-deficiency symptoms were first expressed in 'Red Pac'. Mn-deficient plants appeared pale overall and developed netted chlorosis of the lower leaves (Figure 6). As symptoms advanced, irregular necrotic spotting occurred on the lower leaves and began to move upward in the foliage. 'Black Summer' initially demonstrated similar symptoms, but had bright yellow netted interveinal necrosis (Figure 5). Chlorosis began at the midrib and spread outward to the leaf margins as symptoms progressed, and overall, chlorosis became more pronounced as plants grew.

Foliar Mn concentrations were 70.2\% lower in Mn-deficient 'Black Summer' plants and 80.6\% lower in Mn-deficient 'Red Pac' plants compared to control plants (Tables S1 and S2). Mn-deficient 'Black Summer' plants had foliar concentrations of $23.8 \mathrm{mg} \cdot \mathrm{kg}^{-1} \mathrm{Mn}$, while the control plants had foliar concentrations of $79.8 \mathrm{mg} \cdot \mathrm{kg}^{-1} \mathrm{Mn}$ (Table S1). 'Red Pac' Mn-deficient plants contained $25.4 \mathrm{mg} \cdot \mathrm{kg}^{-1}$ Mn, while control plants contained $131.3 \mathrm{mg} \cdot \mathrm{kg}^{-1} \mathrm{Mn}$ (Table S2). Neither 'Black Summer' nor 'Red Pac' Mn-deficient plants were significantly different in dry mass compared to control plants.

'Black Summer' plants grown under Mn-deficiency did not exhibit statistically different Chl a, $\mathrm{Chl} \mathrm{b}$, or total carotenoid concentrations when compared to control plants (Table S3). In contrast, 'Red Pac' plants without Mn had greatly decreased $\mathrm{Chl}$ a, Chl b, total chlorophyll, and total carotenoids compared to control plants, although anthocyanin concentration was not different (Table S4). Manganese is a non-mobile element and is essential for photosystem II and oxidative-reductive functions [38]. Manganese-deficiency can reduce photosynthesis, cause chlorosis, and ultimately reduce $\mathrm{Chl}$ concentrations [39]. 'Red Pac' may have been more adversely affected by a Mn-deficiency than 'Black Summer' if this element is utilized more heavily in metabolic pathways in 'Red Pac' and is further reduced by lower photosynthesis.

\subsubsection{Boron (B)}

Stunted growth was the first B-deficiency symptom seen in the bok choy cultivars. The stunting proliferated at the growing tips of the B-deficient plants, and a distorted growth pattern also impacted the new leaves. In advanced stages, 'Black Summer' exhibited flaccid and downward-orientated leaves, and in severe cases, death of the meristematic region (Figure 7). 'Red Pac' B-deficient plants exhibited irregular spotting on the lower leaves, which expanded to the leaves in the middle of the plant over time. B-deficient 'Red Pac' plants in the late stages of B-deficiency displayed a large amount of leaf distortion, and in severe cases, death of the growing tip (Figure 8).

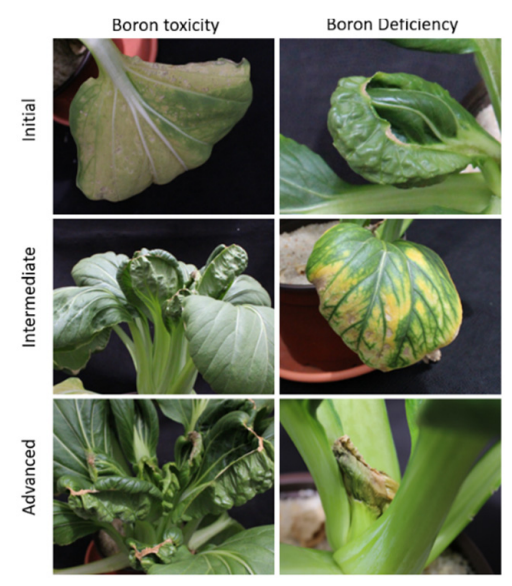

Figure 7. 'Black Summer' boron toxicity and deficiency symptoms for initial, intermediate, and advanced stages. Symptoms of Boron toxicity were initially expressed 35 days after transplant, and boron-deficiency symptoms were observed 21 days after transplant. Plants were continued to be documented until six weeks after transplant to document initial and advanced symptoms. 


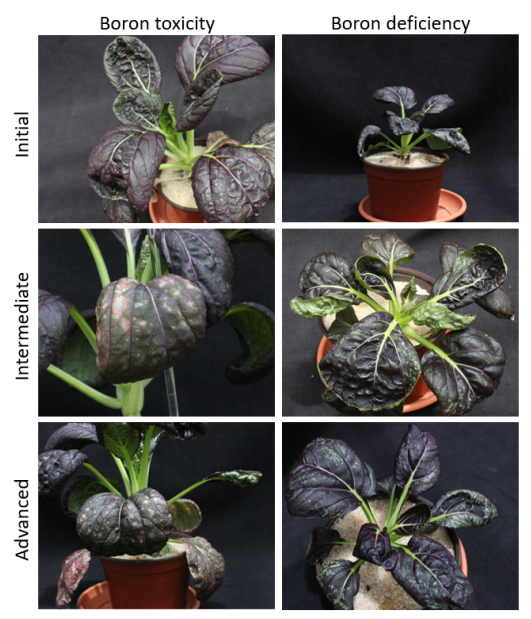

Figure 8. 'Red Pac' boron toxicity and deficiency symptoms for initial, intermediate, and advanced symptoms. Symptoms of Boron toxicity were initially expressed 35 days after transplant, and boron-deficiency symptoms were observed 21 days after transplant. Plants were continued to be documented until six weeks after transplant to document initial and advanced symptoms.

Foliar B concentrations were 79.6\% lower in 'Black Summer' plants and 89.7\% lower in 'Red Pac' plants grown under B-deficient conditions compared to control plants. 'Black Summer' B-deficient plants contained $7.7 \mathrm{mg} \cdot \mathrm{kg}^{-1} \mathrm{~B}$ compared to control plants, which contained $37.8 \mathrm{mg} \cdot \mathrm{kg}^{-1} \mathrm{~B}$ (Table S1). 'Red Pac' B-deficient foliar concentrations were $5.94 \mathrm{mg} \cdot \mathrm{kg}^{-1} \mathrm{~B}$ compared to control plants foliar concentrations, which contained $57.8 \mathrm{mg} \cdot \mathrm{kg}^{-1} \mathrm{~B}$ (Table S2). Dry mass was $57 \%$ less for 'Black Summer' and 72\% for 'Red Pac' in B-deficient plants compared to control plants (Tables S1 and S2). Boron stabilizes the peptide chains within the cell wall of developing plant cells [40]. A lack of stability and structure in the cell walls of the meristematic regions of the plant would result in improper development and atypical cellular morphology. This deformation will result in smaller plants and can also cause the death of the apical meristem, yielding lower plant dry weights.

Chl a, Chl b, total carotenoid concentrations were 64, 57, and 45\% less in 'Black Summer' B-deficient plants when compared to control plants (Table S3). A decrease in boron can cause plants to break down Chl and carotenoids [41]. 'Red Pac' plants grown under B-deficient conditions did not have statistically different $\mathrm{Chl}$ a, Chl b, or total carotenoid concentrations, although total anthocyanin concentration decreased $87 \%$ compared to control plants (Table S4). The loss in chlorophyll in 'Black Summer' and the loss of anthocyanin in 'Red Pac' may indicate differences in resource allocation and/or chloroplast function between cultivars.

\subsubsection{Boron Toxicity}

B-toxicity symptoms initially appeared on the lower leaves as interveinal necrosis on both cultivars (Figures 7 and 8). As symptoms progressed, interveinal chlorosis intensified, and irregular spotting developed. In extreme cases, tan localized necrosis developed. 'Red Pac' developed more severe irregular spotting and had overall paling, starting with the older foliage and transitioning to the middle foliage. As symptoms developed on 'Black Summer', newly expanding leaf tips experienced distortion, and in severe cases, the death of newly expanding foliage tips occurred.

Foliar B concentrations were $<4$ fold and 6-fold higher in the 'Black Summer' and 'Red Pac' plants, respectively, as compared to control plants. B-toxicity increased the foliar B of 'Black Summer' plants to $594.5 \mathrm{mg} \cdot \mathrm{kg}^{-1}$ compared to $48.7 \mathrm{mg} \cdot \mathrm{kg}^{-1}$ in control plants (Table S1). B-toxicity increased foliar boron of 'Red Pac' plants to $231.0 \mathrm{mg} \cdot \mathrm{kg}^{-1}$ compared to $57.8 \mathrm{mg} \cdot \mathrm{kg}^{-1}$ in control plants (Table S2). 'Red Pac' plants grown under B toxicity conditions experienced a $45.7 \%$ decrease in dry mass compared to the control plants (Table S2). Despite the high foliar B concentration, the dry mass of 'Black Summer' plants grown under high B was not statistically different when compared to control plants. B-toxicity 
is known to result in decreased leaf expansion, fruit set, and photosynthetic activity [42]. Only Chl a concentration was decreased in 'Black Summer' (Table S3). Chl a, total carotenoid, and anthocyanin concentrations were 22, 21, and 51\% less in 'Red Pac' leaves from the B toxicity treatment compared to leaves of the control plants (Table S4). There is a wide range in genetic variation in response to $B$ amongst cultivars within the same crop, ranging from very sensitive to moderately tolerant in comparison [43]. This could potentially explain the difference in the impact of B-toxicity on Chl concentrations between these two bok choy cultivars.

\section{3. $S P A D(R C C)$}

Leaf Chl concentration often indicates plant health status [15], and the use of non-destructive meters to determine relative chlorophyll concentration has provided a rapid and fairly accurate assessment of chlorophyll relative to plant stress response [17]. Monitoring leaf Chl concentration can be useful to diagnose N-deficiency and can be done non-destructively through the use of a SPAD meter $[44,45]$. However, SPAD readings have not been correlated to other nutrient deficiencies. Values generally have to be established for each crop and cultivar relative to healthy and unhealthy plant status; values have not been established for bok choy. 'Black Summer' bok choy SPAD readings were near 60, which is in the outer limit of sensitivity for the meter used. Only three treatments, N, Fe, and Mn, exhibited statistically significant SPAD values from the control plants for 'Black Summer'. However, total Chl was significantly lower in N-, Ca-, Mg-, S-, B-, and Fe-deficiency treatments (Table S3). Thus, SPAD values do not serve as a reliable indicator for a significant decrease in $\mathrm{Chl}$ concentrations for 'Black Summer'. SPAD values differed from controls for N, Fe, Mg, S, $+\mathrm{B}$, and $-\mathrm{Mn}$ for 'Red Pac' plants. Whereas, the total $\mathrm{Chl}$ was significantly different for $\mathrm{N}, \mathrm{S}, \mathrm{Fe}, \mathrm{Mn}$, and $+\mathrm{B}$ treatments (Table S4). These results indicate that RCC may be of limited value as an early indicator of chlorophyll loss for dark green bok choy cultivars, such as 'Black Summer'. Moreover, these results show that SPAD readings cannot determine which nutrient deficiency is occurring in a crop. Thus, growers should utilize foliar nutrient analysis to determine nutrient deficiencies prior to making fertility adjustments.

\section{Conclusions}

This research creates a baseline for symptoms and foliar levels of nutrient disorders of Brassica rapa var. Chinensis 'Black Summer' and 'Red Pac' and includes detailed descriptions and high-quality diagnostic images to aid in identifying nutrient disorders. This information can assist growers in determining nutrient problems and decide if fertility adjustments can be made before a loss of quality or yield. Bok choy is a rapidly growing crop that matures in about 45 days after sowing, so plants should be monitored closely for nutrient deficiencies that are quick to develop, such as $\mathrm{N}, \mathrm{P}, \mathrm{K}$, and Fe. In contrast, bok choy deficient in the non-mobile micronutrients, such as $\mathrm{Mo}$ and $\mathrm{Cu}$, did not develop visual symptoms, possibly from the rapid maturation rate of bok choy. The nutrient concentration values established in this study will be useful to growers to adjust immediate or pre-plant fertility decisions for bok choy to mitigate nutrient deficiencies.

Total plant dry weight was reduced in plants with nutrient deficiencies of N, P, Ca, B, and Zn. Dry weights of other nutrient-deficient plants were not affected compared to controls as samples were taken when visual symptoms first developed rather than at intermediate and advanced stages of deficiency. The anthocyanin content of 'Red Pac' was significantly lower compared to control plants for K, Ca, S, B, or +B and may be useful as a symptom of deficiency/toxicity for these nutrients. Chlorophyll content in 'Black Summer' was most impacted by deficiencies in primary nutrients, and estimates of chlorophyll concentration by RCC were useful only for N, Fe, and Mn. Relative Chlorophyll Concentration as an indicator of nutrient deficiency detection was more useful for the anthocyanin producing cultivar 'Red Pac', which has lower SPAD values than 'Black Summer'. 
Supplementary Materials: The following are available online at http://www.mdpi.com/2077-0472/10/10/461/s1, Figure S1: 'Black Summer' control plant that was grown with a complete Hoagland's solution for six weeks after transplant, Figure S2: 'Red Pac' control plant that was grown with a complete Hoagland's solution for six weeks after transplant, Table S1: Leaf tissue nutrient concentration and total plant dry weight of bok choy 'Black Summer', Table S2: Leaf tissue nutrient concentration and total plant dry weight of bok choy 'Red Pac', Table S3: Chlorophyll, total carotenoid, and anthocyanin concentration of bok choy 'Black Summer', Table S4: Chlorophyll, total carotenoid, and anthocyanin concentration of bok choy 'Red Pac', Table S5: Summary table outlining nutrient deficiency symptoms for bok choy.

Author Contributions: The authors contributed to the work as follows: Conceptualization, P.V., P.C., J.H. and B.W.; methodology, P.V., P.C., P.P.-V., and B.W.; software, P.V., P.C., P.P.-V., and B.W.; validation, P.V., P.C., P.P.-V., and B.W.; formal analysis, P.V., P.C., P.P.-V., and B.W.; investigation, P.V., P.C., J.H., P.P.-V., and B.W.; resources, P.P-V. and B.W.; data curation, P.V., P.C. and J.H.; writing-original draft preparation, P.V., P.C., P.P.-V., and B.W.; writing-review and editing, P.V., P.C., J.H., P.P.-V., and B.W.; visualization, P.V., P.C., P.P.-V., and B.W.; supervision, P.P.-V. and B.W.; project administration, P.P-V. and B.W.; funding acquisition, P.P.-V. and B.W. All authors have read and agreed to the published version of the manuscript.

Funding: North Carolina State University Provost's Professional Experience Program for providing partial funding of P.V.'s salary. This research received no external funding.

Acknowledgments: We would like to thank the North Carolina State University Provost's Professional Experience Program for supporting this undergraduate student research project.

Conflicts of Interest: The authors declare no conflict of interest.

\section{References}

1. Cockson, P.; Landis, H.; Smith, T.; Hicks, K.; Whipker, B.E. Characterization of nutrient disorders of Cannabis sativa. Appl. Sci. 2019, 9, 4432. [CrossRef]

2. McCauley, A.; Jones, C.; Jacobsen, J. Plant nutrient functions and deficiency and toxicity symptoms. Nutr. Manag. Modul. 2009, 9,1-16.

3. Gómez-Campo, C. Morphology and Morpho-Taxonomy of the Tribe Brassiceae; Universidad Politecnica: Madrid, Spain, 1980; pp. 3-31.

4. Hill, T.R. The effect of nitrogenous fertilizer and plant spacing on the yield of three Chinese vegetables-Kai lan, Tsoi sum and Pak choi. Sci. Hort. 1990, 45, 11-20. [CrossRef]

5. Averbeke, W.V. Yield response of African leafy vegetables to nitrogen, phosphorus, and potassium: The case of Brassica rapa L. subsp. chinensis and Solanum retroflexum Dun. Water SA 2007, 33, 355-362. [CrossRef]

6. Buer, C.S.; Imin, N.; Djordjevic, M.A. Flavonoids: New roles for old molecules. J. Integr. Plant Biol. 2010, 52, 98-111. [CrossRef] [PubMed]

7. Henry, J.B.; Perkins-Veazie, P.; McCall, I.; Whipker, B.E. Restricted phosphorus fertilization increases the betacyanin concentration and red foliage coloration of alternanthera. J. Am. Soc. Hort. Sci. 2019, 144, $264-273$. [CrossRef]

8. He, J.; Giusti, M.M. Anthocyanins: Natural colorants with health-promoting properties. Ann. Rev. Food Sci. Technol. 2010, 1, 163-187. [CrossRef] [PubMed]

9. Guo, N.; Wu, J.; Zheng, S.; Cheng, F.; Liu, B.; Liang, J.; Cui, Y.; Wang, X. Anthocyanin profile characterization and quantitative trait locus mapping in zicaitai (Brassica rapa L. ssp. Chinensis var. purpurea). Mol. Breed. 2015, 35, 113. [CrossRef]

10. Zhao, X.; Nechols, J.R.; Williams, K.A.; Wang, W.; Carey, E.E. Comparison of phenolic acids in organically and conventionally grown pac choi (Brassica rapa L. Chinensis). J. Sci. Food Agric. 2009, 89, 940-946. [CrossRef]

11. Deroles, S. Anthocyanin biosynthesis in plant cell cultures: A potential source of natural colourants. In Anthocyanins; Springer: New York, NY, USA, 2008; pp. 108-167.

12. Passeri, V.; Koes, R.; Quattrocchio, F.M. New challenges for the design of high value plant products: Stabilization of anthocyanins in plant vacuoles. Front. Plant Sci. 2016, 7, 153. [CrossRef]

13. Kalaji, H.M.; Dabrowski, P.; Cetner, M.D.; Samborska, I.A.; Łukasik, I.; Brestic, M.; Zivcak, M.; Tomasz, H.; Mojski, J.; Kociel, H.; et al. A comparison between different chlorophyll content meters under nutrient deficiency conditions. J. Plant Nutr. 2017, 40, 1024-1034. [CrossRef]

14. Demmig-Adams, B. Carotenoids and photoprotection in plants: A role for the xanthophyll zeaxanthin. Biochim. Biophys. Acta (BBA)-Bioenerg. 1990, 1020, 1-24. [CrossRef] 
15. Hlavinka, J.; Nauš, J.; Špundová, M. Anthocyanin contribution to chlorophyll meter readings and its correction. Photosynth Res. 2013, 118, 277-295. [CrossRef] [PubMed]

16. Curran, P.J.; Dungan, J.L.; Gholz, H.L. Exploring the relationship between reflectance red edge and chlorophyll content in slash pine. Tree Physiol. 1990, 7, 33-48. [CrossRef] [PubMed]

17. Li, Z.; Liu, H.; Zhang, Y. A review on chlorophyll meter application on nitrogen fertilizer recommendation. Plant Nutr. Fert. Sci. 2006, 1, 125-132.

18. Bryson, G.M.; Mills, H.A. Plant Analysis Handbook IV; Micro-Macro Publishing: Athens, GA, USA, 2015; pp. 1-600.

19. Barnes, J.; Whipker, B.; McCall, I.; Frantz, J. Nutrient disorders of ‘Evolution' mealy-cup sage. HortTechnology 2012, 22, 502-508. [CrossRef]

20. Lichtenthaler, H.K. Chlorophyll and carotenoids: Pigments of photosynthetic biomembranes. Methods Enzymol. 1987, 148, 350-382.

21. Lee, J.; Rennaker, C.; Wrolstad, R.E. Correlation of two anthocyanin quantification methods: HPLC and spectrophotometric methods. Food Chem. 2008, 110, 782-786. [CrossRef]

22. Lancien, M.; Ferrario-Méry, S.; Roux, Y.; Bismuth, E.; Masclaux, C.; Hirel, B.; Gadal, P.; Hodges, M. Simultaneous expression of NAD-dependent isocitrate dehydrogenase and other Krebs cycle genes after nitrate resupply to short-term nitrogen-starved tobacco. Plant Physiol. 1999, 120, 717-726. [CrossRef]

23. Bhaskar, R.; Bondada, J.; Syvertsen, P. Leaf chlorophyll, net gas exchange and chloroplast ultrastructure in citrus leaves of different nitrogen status. Tree Physiol. 2003, 23, 553-559.

24. Soubeyrand, E.; Basteau, C.; Hilbert, G.; van Leeuwen, C.; Delrot, S.; Gomès, E. Nitrogen supply affects anthocyanin biosynthetic and regulatory genes in grapevine cv. Cabernet-sauvignon berries. Phytochemistry 2014, 103, 38-49. [CrossRef] [PubMed]

25. Sarker, B.; Karmoker, J. Effects of phosphorus deficiency on accumulation of biochemical compounds in lentil. Bangladesh J. Bot. 2011, 40, 23-27. [CrossRef]

26. Desikan, R.; Cheung, M.K.; Bright, J.; Henson, D.; Hancock, J.T.; Neill, S.J. ABA, hydrogen peroxide and nitric oxide signalling in stomatal guard cells. J. Exper. Bot. 2004, 55, 205-212. [CrossRef] [PubMed]

27. Besford, R.T. Effect of potassium nutrition on leaf protein concentrations and growth of young tomato plants. Plant Soil 1975, 42, 441-451. [CrossRef]

28. Wang, Y.; Wu, W.H. Potassium transport and signaling in higher plants. Ann. Rev. Plant Biol. 2013, 64, 451-476. [CrossRef]

29. Oosterhuis, D.M.; Bednarz, C.W. Physiological changes during the development of potassium deficiency in cotton. Plant nutrition for sustainable food production and environment. Dev. Plant Soil 1997, 78, 347-351.

30. Delgado, R.; Martín, P.; Del Álamo, M.; González, M.R. Changes in the phenolic composition of grape berries during ripening in relation to vineyard nitrogen and potassium fertilization rates. J. Sci. Food Agric. 2004, 84, 623-630. [CrossRef]

31. Marchiosi, R.; dos Santos, W.D.; Constantin, R.P.; de Lima, R.B.; Soares, A.R.; Finger-Teixeira, A.; Mota, T.R.; de Oliveira, D.M.; Foletto-Felipe, M.d.P.; Abrahão, J. Biosynthesis and metabolic actions of simple phenolic acids in plants. Phytochem. Rev. 2020, 19, 865-906. [CrossRef]

32. Brand, J.J.; Becker, D.W. Evidence for direct roles of calcium in photosynthesis. J. Bioenerg. Biomembr. 1984, 16, 239-249. [CrossRef]

33. Shaul, O. Magnesium transport and function in plants: The tip of the iceberg. Biometals 2002, 15, 307-321. [CrossRef]

34. Gransee, A.; Führs, H. Magnesium mobility in soils as a challenge for soil and plant analysis, magnesium fertilization, and root uptake under adverse growth conditions. Plant Soil 2013, 368, 5-21. [CrossRef]

35. Terry, N. Effects of sulfur on the photosynthesis of intact leaves and isolated chloroplasts of sugar beets. Plant Physiol. 1976, 57, 477-479. [CrossRef] [PubMed]

36. Kaur, N.P.; Takkar, P.N.; Nayyar, V.K. Catalase, peroxidase, and chlorphyll relationships to yield and iron deficiency chlorosis in Cicer genotypes. J. Plant Nutr. 1984, 7, 1213-1220. [CrossRef]

37. Shi, P.; Li, B.; Chen, H.; Song, C.; Meng, J.; Xi, Z.; Zhang, Z. Iron supply affects anthocyanin content and related gene expression in berries of Vitis vinifera cv. Cabernet Sauvignon. Molecules 2017, 22, 283. [CrossRef] [PubMed]

38. Mousavi, S.R.; Shahsavari, M.; Rezaei, M. A general overview on manganese (Mn) importance for crops production. Australian J. Basic Appl. Sci. 2011, 5, 1799-1803. 
39. Singh, P.; Misra, A.; Srivastava, N. Influence of Mn deficiency on growth, chlorophyll content, physiology, and essential monoterpene oil(s) in genotypes of spearmint (Mentha spicata L.). Photosynthetica 2001, 39, 473-476. [CrossRef]

40. Matoh, T. Boron in plant cell walls. Plant Soil 1997, 193, 59-70. [CrossRef]

41. Hua, Y.; Feng, Y.; Zhou, T.; Xu, F. Genome-scale mRNA transcriptomic insights into the responses of oilseed rape (Brassica napus L.) to varying boron availabilities. Plant Soil 2017, 416, 205-225. [CrossRef]

42. Nable, R.O.; Bañuelos, G.S.; Paull, J.G. Boron toxicity. Plant Soil 1997, 193, 181-198. [CrossRef]

43. Moody, D.B.; Rathjen, A.J.; Cartwright, B.; Paull, J.G.; Lewis, J. Genetic diversity and geographical distribution of tolerance to high levels of soil boron. In Seventh International Wheat Genetics Symposium; Miller, T.E., Koebner, R.M.D., Eds.; Institute of Plant Science Research: Cambridge, UK, 1988; pp. 859-865.

44. Debaeke, P.; Rouet, P.; Justes, E. Relationship between the normalized SPAD index and the nitrogen nutrition index: Application to durum wheat. J. Plant Nutr. 2006, 29, 75-92. [CrossRef]

45. Loh, F.C.; Grabosky, J.C.; Bassuk, N.L. Using the SPAD 502 meter to assess chlorophyll and nitrogen content of benjamin fig and cottonwood leaves. HortTechnology 2002, 12, 682-686. [CrossRef]

(C) 2020 by the authors. Licensee MDPI, Basel, Switzerland. This article is an open access article distributed under the terms and conditions of the Creative Commons Attribution (CC BY) license (http://creativecommons.org/licenses/by/4.0/). 